\title{
Cross-Racial Envy and Underinvestment in South Africa
}

\author{
Daniel Haile, Abdolkarim Sadrieh, and Harrie A.A. Verbon \\ Wageningen University, University of Magdeburg, Tilburg University
}

January 2006

\begin{abstract}
Trust games are employed to investigate the effect of heterogeneity in income and race on cooperation in South Africa. The amount of socio-economic information available to the subjects about their counterparts is varied. No significant behavioural differences are observed, when no such information is provided. However, when the information is available, it significantly affects individual trust behaviour. The low income subjects from both racial groups invest significantly less in partnerships with the high income subjects of the other racial group than in any other partnership. We attribute this behaviour to cross-racial envy, which on aggregate may lead to substantial underinvestment in the economy.
\end{abstract}

JEL Classification: C91, H55

Keywords: trust game, ethnic diversity, income inequality, cooperation

\section{Contacting the Authors}

Daniel Haile, Wageningen University (d.haile@uvt.nl)

Abdolkarim Sadrieh, Faculty of Economics and Management, University of Magdeburg (sadrieh@ww.unimagdeburg.de)

Harrie A.A. Verbon, Department of Economics, Tilburg University, CentER for Economic Research (H.A.A.Verbon@uvt.nl) 


\section{Introduction}

A recent hypothesis in the literature is that economic performance will be furthered by the absence of economic and ethnic divisions (see e.g. Easterly and Levine, 1997 and Alesina et al., 1999). Knack and Keefer (1997), for example, note that for countries like Norway, Finland, Sweden, Denmark and Canada, a high degree of homogeneity both in terms of income and ethnicity goes along with a high degree of economic performance. ${ }^{1}$ The explanation behind this linkage is that people with a greater set of similar characteristics are more likely to form partnerships and start to cooperate. ${ }^{2}$

In this paper, we examine the effect of economic and ethnic division in the case of the South African society. This society is extreme in its heterogeneity, with segmentation along both racial and income divides. In particular, before the break down of apartheid in 1994, the black population $^{3}$ received less than $50 \%$ of the national income, but this share had risen to $75 \%$ in $1995^{4}$ (Stewart 2000). However, at the same time intra-racial income inequality had increased. Amongst black households the Gini index increased from 0.49 in 1970 to 0.59 in 2000, while among the whites it moved from 0.43 to 0.49 (Whiteford and van Seventer 2000).

Widening income gaps within ethnic groups can imply low intra-group trust levels, next to the low trust between groups. To study both aspects of the trust problem, we conducted trust game experiments in South Africa, in which the subjects were given information about their opponents' race and income characteristics. The trust game, originally developed by Berg, Dickhaut, and McCabe (1995), is a two-player game in which the first player, the sender, sends part of his initial endowment to the second player, the receiver. The experimenter triples the sent amount, and the receiver can then decide which part of his total endowment (the tripled transferred amount plus the initial endowment) to return to the sender. The game is called a trust game as the amount the sender transfers to the receiver gives an indication of the sender's trust in the willingness of the receiver to reciprocate. The trust game has emerged

\footnotetext{
${ }^{1}$ Incidentally, based on the World Social Survey measurement, these five countries also have the highest level of trust. The close correlation between trust, social homogeneity and economic performance can also be derived from the experimental results by Glaeser et al. (2000) who find that when individuals are closer socially, trust and trustworthiness tend to be higher.

${ }^{2}$ However, as shown by Collier (2001), democracy may considerably soften the detrimental effects of ethnic diversity on economic growth.

${ }^{3}$ According to the 1996 census $77 \%$ of the $40,583,573$ people in the country were black and $11 \%$ were white, while Indians (3\%) and colored (9\%) people made up smaller percentages.
} 
as one of the leading experimental instrument for the measurement of the level of cooperativeness in societies (see Glaeser et al. 2000; Camerer 2003)

We employ the trust game to assess the degree to which racial and income disparity may be degrading trust and, thus, hampering economic development in South Africa. More specifically, the questions that we raise include: Is the level of trust and cooperative attitude in the South African society generally (disregarding specific race and income disparities) different from what has been reported in the literature on other societies? In what ways does information on the race and the income characteristics of a trading partner determine the level of trust and reciprocity in the multiply segmented South African society? The answers to these questions are obviously vital to economic and social development, because trust and cooperation across racial and income boundaries will be necessary in order to reduce transaction costs and, thus, to enhance economic exchange and efficiency.

While several experimental studies have examined the effect of ethnicity on trust and trustworthiness, no study so far has attempted to disentangle the ethnicity effects from the income inequality effects. Gneezy and Fershtman (2001) studied Israeli partnerships in which the individuals were informed on their partner's last name. Since last names in Israel are generally indicative of the pre-immigration ethnicity, the names may be used to discriminate between partners from different ethnical origins. In fact the study shows a systematic mistrust of "eastern" males resulting in a lower efficiency of the partnerships they were involved in. On first sight, this outcome seems to imply a clear case for ethnic discrimination. But, a closer look at the income distribution across the ethnic divide reveals that there may have been an effect of income inequality that confounded the results. Since individuals of "eastern" origin are much more likely to be in the lower income groups (see Gneezy and Fershtman 2001) and since the actual income level of the subjects was not controlled for, it remains unclear, whether the discrimination (i.e. the distrust) was towards the "eastern" males or towards "poor" males.

In a study with US subjects, Eckel and Wilson (2003) find that allowing individuals to observe their partner's picture increases trust and trustworthiness. However, they also find that the pictures can lead to ethnic discrimination, because minority groups (in particular African-Americans) are less likely to be trusted than the majority groups (Caucasian). Again,

\footnotetext{
${ }^{4}$ South Africa had a Gini Index of 0.58 in 1997 , which made it the country with the highest inequality after Brazil with a Gini index of 0.63 (World Bank, 1997).
} 
there is no control for the income distribution effects, which happen to point in the same direction as in the Gneezy and Fershtman study: The ethnic group that is mistrusted happens to be the ethnic group with the lower average income.

In a study with South African subjects, Burns (2003) conducted dictator and trust games with high school students in the greater Cape Town area. ${ }^{5}$ To check the effect of race on the propensity to trust, subjects were shown pictures of their partners. In the dictator games, blacks are favoured by non-whites, but not by whites, who show no bias towards any race. In trust games, however, black students are trusted less by all groups, including their own group. Once again, this seems to be clear evidence for the prevalence of racial discrimination, but there is no control for possible confounding effects of income inequality. As in the other two studies, the group that is being mistrusted most also represents the poorest ethnic group, leaving the question open, whether racial or income discrimination has been detected here.

Our experimental design allows us to disentangle the two main division lines that exist in heterogeneous societies (i.e. the racial or ethnic and the income divides) by giving subjects information both on the income level and the race of their partner. Surprisingly, we find neither a purely racial nor a purely income-based discrimination effect. Instead, we discover a strong and significant intra-racial envy effect that - to our knowledge - has not been reported by any study so far. We find that the low income individuals of both races invest little in partnerships with a high income partner from the other race. This effect can be considered a robust discrimination effect, because behaviour in the baseline treatment without information, which we conducted with a randomised sub-sample of our subjects, neither exhibits significant differences within the subject pool, nor significant differences when compared to the behaviour observed in earlier experiments without information.

We proceed in the following fashion. Section 2 describes the experimental protocol. Section 3 contains the results on the effects of information. In particular it discusses whether discrimination, if it exists, is based on income or on race. Section 4 figures out the correlates

\footnotetext{
${ }^{5}$ Experimental studies on trust in (South) Africa using experiments are rare. Barr (2003) conducted experiments in Zimbabwe in order to detect which factors contribute to the feeling of shared social identities within communities. Carter and Casteillo (2003) examine the level of trust for South African communities in the province of KwaZulu-Natal, investigating the difference between rural or urban communities in the degree of intra-racial trust. In a closely connected study, Haddad and Maluccio (2003) conduct household-level research in KwaZulu-Natal. Their results suggest that both local trust (in neighbours and extended family) and income level are important for financial group participation, which is shown to be correlated with economic prosperity.
} 
of survey questions with experimental decisions and thereby analyzes the impact of social distance on the propensity to trust. The last section concludes.

\section{Experimental Procedures}

The subjects played the one-shot trust game. We applied the strategy method, where each subject decided how much to transfer both in the role of sender and the role of receiver. ${ }^{6}$ Subjects knew at the start of the experiment that they had to play both roles. The role that determined the actual payoff was drawn randomly. Both sender and receiver were endowed with 20 Rand. (At the time of the experiment the exchange rate was $€ 1=7.8$ Rand). As senders, subjects were asked to decide how much of their endowment they would like to transfer to a receiver. To decrease decision complexity and paperwork, the sender transfer was restricted to being zero or any even integer smaller or equal to 20 . As receivers, subjects were asked to decide how much they would like to transfer back for each of the 11 possible amounts $(0,2, \ldots, 20)$ that they may have received from a sender. Additionally, each subject was asked to report both the amount expected as a return on the own transfer as a sender and the amount expected as an investment as a receiver. ${ }^{7}$

Our treatment variable is the information that subjects received on the characteristics of their counterparts. Upon recruitment, subjects were asked to report their race $^{8}$ and to compare their family income to average family income in South Africa. Based upon this self-assessment information, we categorized our subjects according to their race $(\mathrm{B}=$ black; $\mathrm{W}=$ white $)$ and their income level ( $\mathrm{L}=$ low income, i.e. below average; $\mathrm{H}=$ high income, i.e. above average). In the "information" treatment, the information both on the race and the income level of the counterpart was given to each subject before any decision was made. In the "no information" treatment, no such information was given to subjects. The experimental conditions, including the number of observations for all the distinguished subject types and treatments, are summarized in Table 1.

\footnotetext{
${ }^{6}$ We applied the strategy method, as we had to recruit a large part of our subjects on the spot and did not know in advance whether a counterpart for each recruited subject could be found.

${ }^{7}$ The instructions to the subjects are contained in the appendix.

${ }^{8}$ In South Africa students are normally asked to indicate their race upon registering for a university or a school. Hence, asking for this information does not have to generate suspicion with the subjects regarding the experimenters' intentions. No single subject objected to providing the information on the race.
} 
A total of 172 subjects participated in the experiment, 94 black and 78 white. 112 considered their family income to be below average and 60 above. ${ }^{9}$ Obviously, the population distribution at the universities is not equivalent to the distribution of race and income in the general population of South Africa. But, note that this does not disturb the internal validity of our experimental investigation, because the socio-economic matching that we used in each partnership was pre-defined and known to the subjects. Hence, the population distribution played absolutely no role in the decision-making and the evaluation of the results.

Table 1. Experimental conditions and number of observations in South Africa trust game.

\begin{tabular}{|c|c|c|c|c|c|c|c|}
\hline & & \multirow{2}{*}{ No information* } & \multicolumn{4}{|c|}{ Information* } & \multirow{2}{*}{ Total } \\
\hline & & & BL & $\mathrm{BH}$ & WL & WH & \\
\hline \multirow{5}{*}{ Subjects' characteristics } & BL & 15 & 15 & 15 & 15 & 20 & 80 \\
\hline & $\mathrm{BH}$ & 1 & 6 & 1 & 0 & 6 & 14 \\
\hline & WL & 4 & 4 & 7 & 7 & 10 & 32 \\
\hline & WH & 8 & 9 & 8 & 10 & 11 & 46 \\
\hline & Total & 28 & 34 & 30 & 32 & 47 & 172 \\
\hline
\end{tabular}

*) In the "information" treatment, subjects were given both race and income level information on their counterpart before the transfer decisions were made. No such information was given at any time in the "no information" treatment.

The experimental sessions were conducted in October 2003, at the Potchefstroom University ${ }^{10}$ (predominantly white) and at the Mafeking University (predominantly black). We conducted the experiment using pen and paper. A post-experimental questionnaire, containing some general questions and some standardized items on equity preferences, was solicited from each subject after the experiment (see Appendix XX). After all sessions were completed, each subject's decision form was linked to that of another subject, respecting the pre-determined matching that was recorded on the subject's decision form. ${ }^{11}$ Next, the role of the subject in

\footnotetext{
${ }^{9}$ We used an open advertisement recruiting procedure at the two universities visited. Even though the student population can be considered as biased towards the high income groups, the frequency of high income blacks in the population is so low, that we were not able to recruit as many $\mathrm{BH}$ subjects as we had initially planned.

10 Conducting the experiments was made possible by the hospitality of the Economics Department of Potchefstroom University; especially professor Wim Naudé's support was indispensable.

11 Note that the strategy method guarantees that each decision form can be considered an independent observation, because no interaction has taken place, when subjects make their decisions. Furthermore the strategy method guarantees that we can match unbalanced groups without letting any subject play more than once and without deceiving subjects.
} 
the partnership was determined randomly and with equal probabilities. Finally, the subject's payoff was calculated using the linked decision forms and the subjects were paid in cash.

\section{Results}

\subsection{Outcomes without race and income information}

In the original trust game of Berg et al. (1995) subjects were not provided with any socioeconomic information on their counterparts. Nevertheless, it is clear that the subjects had some general notion of the cultural environment, in which their partnerships were. All subjects in that study were university students in the USA. Our subject pool is similar, because all our subjects are university students in South Africa. Clearly, a basic assessment of the general level of trust and trustworthiness exhibited by our subjects is necessary to ensure comparability of our results concerning the main treatment effects (i.e. the effect of socioeconomic information on behaviour). Hence, we conducted the "no information" treatment, which provides us with such a general benchmark, because it elicits behaviour with the same amount of socio-economic information as was given in the original study. In other words, by comparing the results of our "no information" treatment to the results of Berg et al. (1995), we can examine in which way trust and trustworthiness in South African student communities differs from the US students behaviour, when behaviour in both cases is elicited in absence of socio-economic discrimination effects.

Table 2 presents summary statistics on the original study by Berg et al. (1995) and our two treatments. The table displays the number of independent observations, the initial endowment size, the observed proportion of senders transferring zero, the average investment ratio (i.e. the ration of the sent amount to the endowment), and the average return ratio (i.e. the ratio of the amount returned to the initial endowment plus received transfer). It is striking how close the values of the three observational variables are, when we compare our "no information" data to the original data. In fact, statistical tests confirm that there is no difference between the behaviour of US and South African subjects in the trust game. ${ }^{12}$

\footnotetext{
${ }^{12}$ We use the Mann-Whitney U-test to check for location differences between the Berg et al. (1995) data and our "no information" data. We neither find significant differences (not even on a $20 \%$, one-tailed level) in the portion of senders sending zero, nor in the investment ratio, nor in the return ratio.
} 
Table 2. Comparison of Behaviour of Subjects in Berg et al. (1995) and South Africa

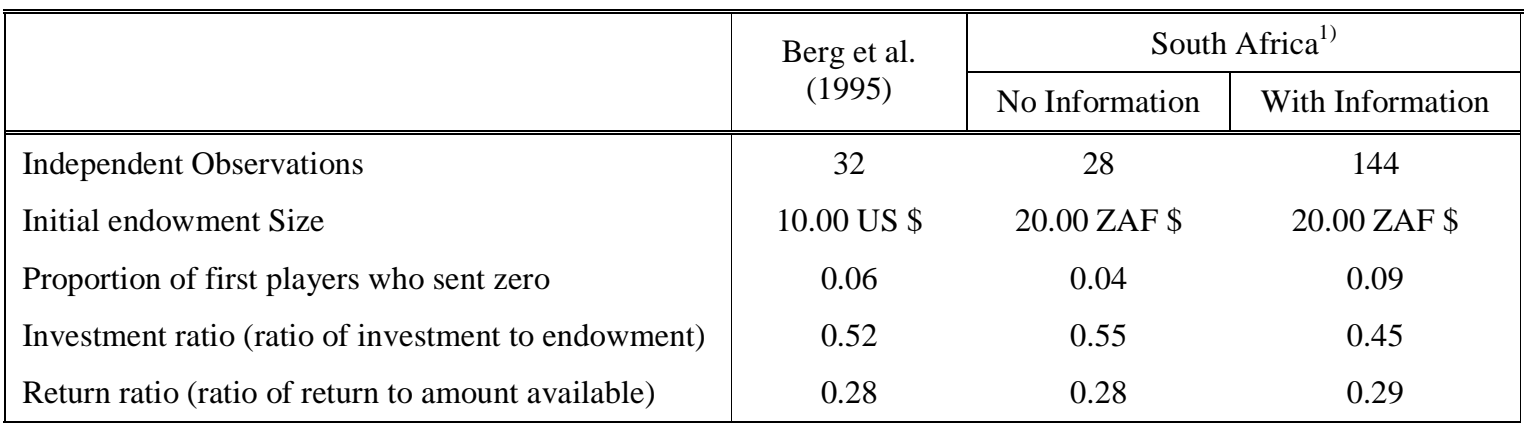

1) In Berg et al. (1995), second players make responses only when senders invest more than zero while in South African experiment subjects continue to play as we used the strategy method.

Interestingly, this result also goes through, if we compare the behaviour of the subjects in each of the socio-economic groups of the "no information" treatment separately. Table 3 reports the investment ratio (both actual and anticipated) as well as the return ratio (both actual and anticipated) for the sub-samples in the "no information" treatment. ${ }^{13}$ Trusting and reciprocating behaviour in none of the sub-sample groups of the "no information" treatment is statistically different from the behaviour of the Berg et al. (1995) subjects. Furthermore, none of the across sub-sample comparisons (e.g. BL vs. WL, BL vs. WH etc.) reveals a significant difference in behaviour. Thus, despite the fact that the South African society is rather heterogeneous, it seems that the general level of trust and trustworthiness (as measured by the trust game) is similar to the level found in more homogenous societies (Camerer 2003) when discrimination based on the race or income information is not possible.

Table 3. Average percentages of available amounts in the "no information" treatment.

\begin{tabular}{|lccc|}
\hline Socio-economic group & BL & WL & WH \\
\hline \hline Investment ratio & 0.56 & 0.60 & 0.56 \\
Anticipated investment ratio & 0.62 & 0.70 & 0.61 \\
Return ratio & 0.30 & 0.26 & 0.30 \\
Anticipated return ratio & 0.31 & 0.33 & 0.33 \\
\hline
\end{tabular}

\footnotetext{
${ }^{13}$ The BH sub-sample is left out of this analysis, due to the very small number of observations we have.
} 


\subsection{Aggregate outcomes with race and income information}

The last column of Table 2 displays the average aggregate outcomes in the "information" treatment, in which subjects were given socio-economic information on their counterparts. Despite the fact that there are a few more investors sending 0 and that the average aggregate investment is slightly lower in the "information" than in the "no information" treatment, we do neither observe strong and significant differences when comparing our treatments to one another, nor when comparing them to the results of Berg et al. (1995). Even a closer look at the relationship between the invested amount and the return ratio, does not reveal any behavioural differences on the aggregate level. As displayed by Figure 1, the way the average return ratio increases with the investment level seems to be very similar both with and without socio-economic information.

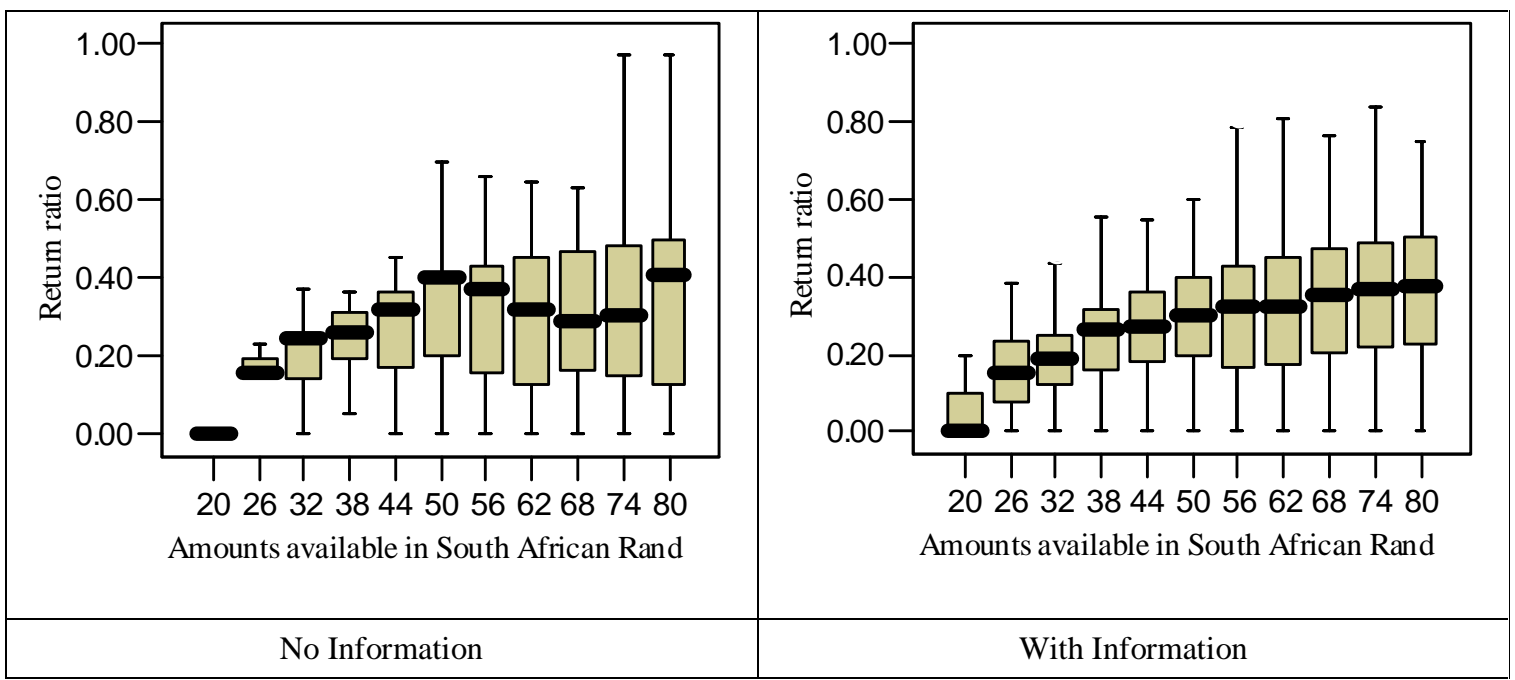

Figure 1. Aggregate return ratio at different investment levels.

\subsection{Group specific investment decisions with race and income information}

While the effect of race and income information seems rather small in the aggregate, we can use our detailed data to analyse whether differences exist between the socio-economic groups. ${ }^{14}$ Figure 2 shows the average investment ratio exhibited by the subjects in each of the four socio-economic sub-samples $(\mathrm{BL}, \mathrm{BH}, \mathrm{WL}$, and $\mathrm{WH})$ of the "information" treatment when facing a receiver from their own or from each of the other groups. To facilitate the

\footnotetext{
${ }^{14}$ Even more detailed information on the average investment and the return ratios, as well as the anticipations thereof, is presented for all groups and treatments in Appendix A.
} 
comparisons, the average investment ratios are shown as deviations from the average investment ratio in the "no information" treatment (i.e. 0.55). We use the behaviour in the "no information" treatment as a benchmark, because it cannot be biased by any deliberate discrimination that specifically targets the socio-economic group of the counterpart. Furthermore, since we have established that the behaviour in our "no information" treatment is indistinguishable from the trust game behaviour observed in completely different cultural settings, the "no information" benchmark seems to exhibit a certain degree of universality.

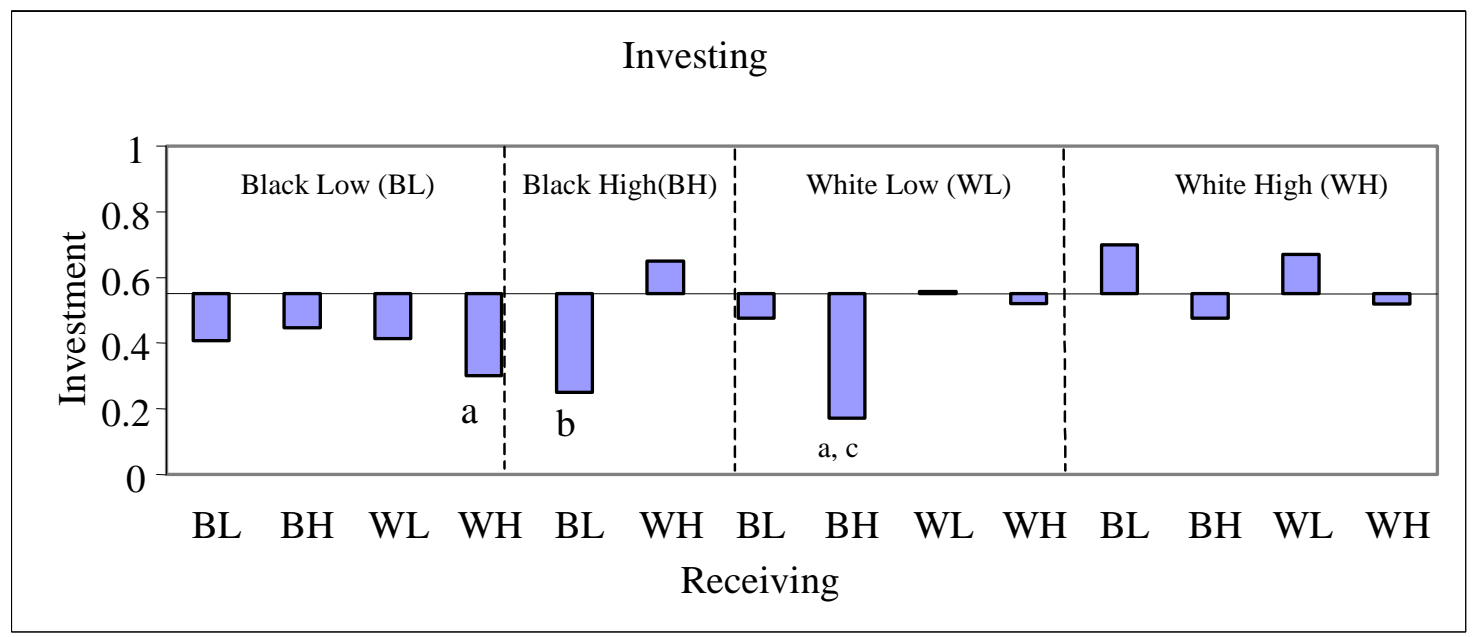

Figure 2. Average investment ratio

Note: The bars represent the average investment ratio in each socio-economic group (sub-title on top) in partnerships with subjects of each socio-economic group (indicated on the X-axis). (a) Significantly lower investment ratio in partnerships with WH receivers than in the no information benchmark. (b) Significantly lower investment ratio in partnerships with BL than with WH. (c) Significantly lower investment ratio in partnerships with $\mathrm{BH}$ than with any other socio-economic group (WH, WL and BL).

The left most section of Figure 2 displays the average investment ratios chosen by BLsubjects in each of their four possible partnerships. Although all four averages lie below the benchmark of the "no information" treatment, only investment ratios in partnerships with WH-subject are on average significantly below the benchmark. ${ }^{15}$ The third section of Figure 2 shows that WL-subjects also tend to invest less when they have socio-economic information on their counterpart than when they do not. Exactly as in the case of the BL-subject, a crossracial relationship specifies the only partnership, in which the WL-subjects' investments are

\footnotetext{
${ }^{15}$ We compare the group's decisions with the overall averages (benchmark case). It would not change our results, if comparison were made with group averages. Moreover, we do not find any statistically significant differences in the behaviour of the BL subjects when comparing locations, i.e. Potchefstroom to Mafikeng.
} 
significantly lower than in the "no information" benchmark. The average investment ratio of the WL-subjects in informed partnerships with BH-subjects is just above 17\%, which is not only dramatically and significantly less than the average $60 \%$ investment ratio of WL-subjects in the "no information" treatment, but also significantly less than any of their average investment ratio in partnerships with any of the other three groups $(47.5 \%, 55.7 \%$, and $52 \%$ for $\mathrm{BL}, \mathrm{WL}$, and $\mathrm{WH}$, respectively).

The second and fourth sections of Figure 2 show that while WH-subjects on average do not differentiate their investments by socio-economic categories (i.e. there are no significant effects of the socio-economic information on investment behaviour), the BH-subjects do. The average investment of BH-subjects in partnerships with BL-subjects is significantly lower than their average investment in partnerships with WH- subjects. The average investment ratio of $\mathrm{BH}$ in BL-partnerships (25\%) is also substantially below the $\mathrm{BH}$ average investment ratio in the "no information" benchmark (55\%). The lack of statistical significance in this comparison is most probably due to the relatively small number of observations with $\mathrm{BH}$ subjects.

The fact that subjects differentiate their investments according to the socio-economic characteristics of their counterpart can be based either on a preference for discrimination or on distrust. Distrust towards a certain other group may not be justified, i.e. that group may actually be trustworthy on average, but thought to be the contrary, perhaps due to wide-spread prejudices in the investor group. In this case, we do not observe a personal preference for discrimination, but a societal tendency. Finally, if the distrust is actually justified, because the average return by partners from the specific socio-economic group is below the return by others, then the low investment may be solely driven by economic incentives and completely free of a preference for discrimination.

Figure 3 shows that subjects in two of three cases, in which we observe extremely low investment ratios, $\mathrm{BL}$ in partnerships with $\mathrm{WH}$ and $\mathrm{BH}$ with $\mathrm{BL}$, are mainly driven by a preference for discrimination. In both of these cases, the expected average return ratio of the group discriminated against is not lower than that of any other group. Hence, since subjects on average expect a similar return to their investment, there is no economic reason to invest significantly less in one project than in the other. In contrast, the extremely low investment case that we observed, WL in partnerships with $\mathrm{BH}$, actually seems to be based on economic motives, since the WL-subjects on average expect significantly lower return ratios in partnerships with black counterparts than with white counterparts. While it seems clear that 
the WL-subjects keep investments to BL and BH-subjects low, because they distrust them, it is not obvious, whether this distrust is actually justified or whether it is a form of "second order" discrimination, because it is based on prejudices and false beliefs concerning the economic behaviour of a specific socio-economic group. As the analysis of the actual return behaviour in the next sub-section shows, the latter is the case, i.e. the low expectations that the WL-subjects have concerning the return behaviour of $\mathrm{BL}$ and $\mathrm{BH}$-subjects turn out to be wrong. This obviously leaves the question open, why the WL-subjects have such a grossly wrong opinion on the behaviour of the $\mathrm{BL}$ and $\mathrm{BH}$-subjects.

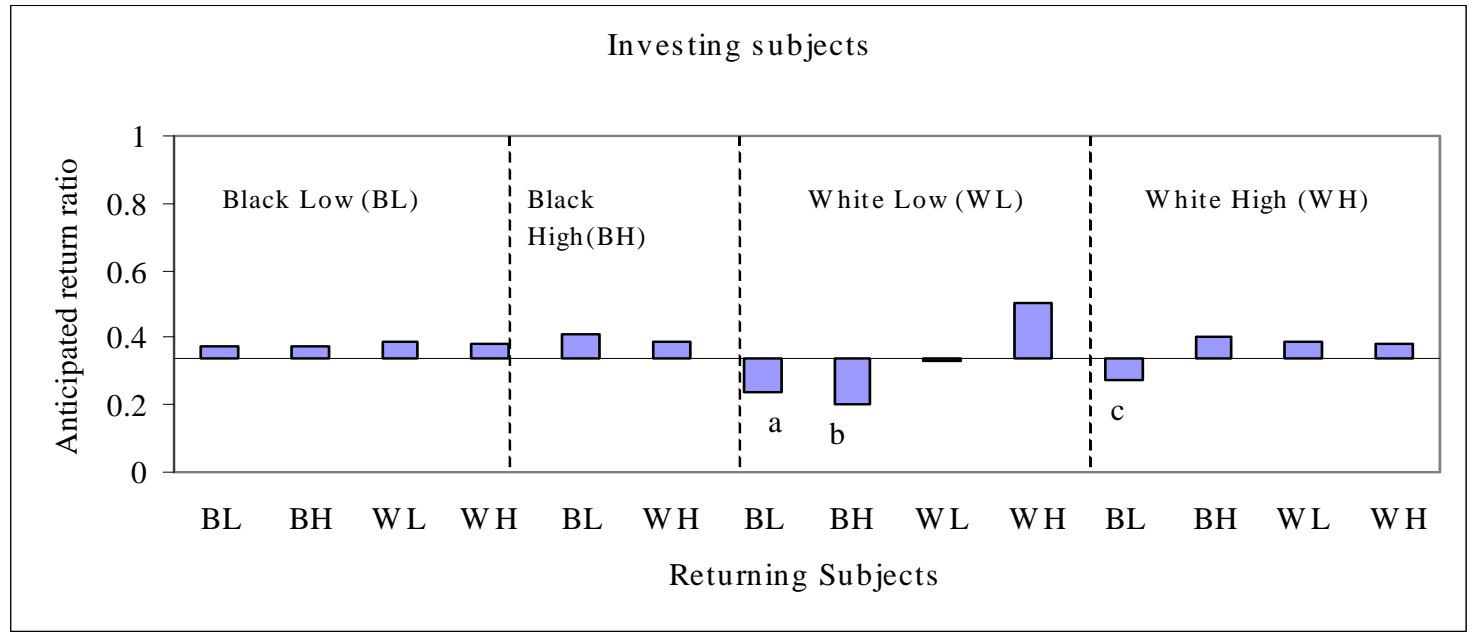

Figure 3. Average anticipated return ratio

Note: The bars represent the average return ratio expected in each socio-economic group (sub-title on top) in partnerships with subjects of each socio-economic group (indicated on the X-axis). (a) Significantly lower return ratio expected in partnerships with BL than with WH. (b) Significantly lower return ratio expected in partnerships with BH than with WH. (c) Significantly lower return ratio expected in partnerships with BL than with $\mathrm{BH}$

\subsection{Group specific return decisions with race and income information}

Figure 4 indicates the average return ratio chosen by the subjects of each socio-economic group in their partnerships with subjects of different socio-economic groups. None of the average return ratios is significantly different from the average return ratio observed in the "no information" treatment. Furthermore, there is only a single case in which the subjects of one group significantly differentiate their return responses on the basis of the socio-economic characteristics. BL subjects exhibit lower return ratios in partnerships with WH subjects than with WL subjects. This seems to correspond to the cross-racial envy effect that we also 
observe concerning the investment ratio of the BL subjects. It seems that WH subjects are generally treated somewhat worse by the BL subjects. Note first, that this behaviour must be driven by some non-monetary motivation, because the BL subjects invest less in partnerships with WH subjects even though they do not expect lower returns. Note also, that the adverse treatment of WH subjects by BL subjects cannot be a purely racial differentiation effect, since we observe a (insignificantly) higher average return ratio of the BL subjects in partnerships with WL subjects than in any partnership with black subjects.

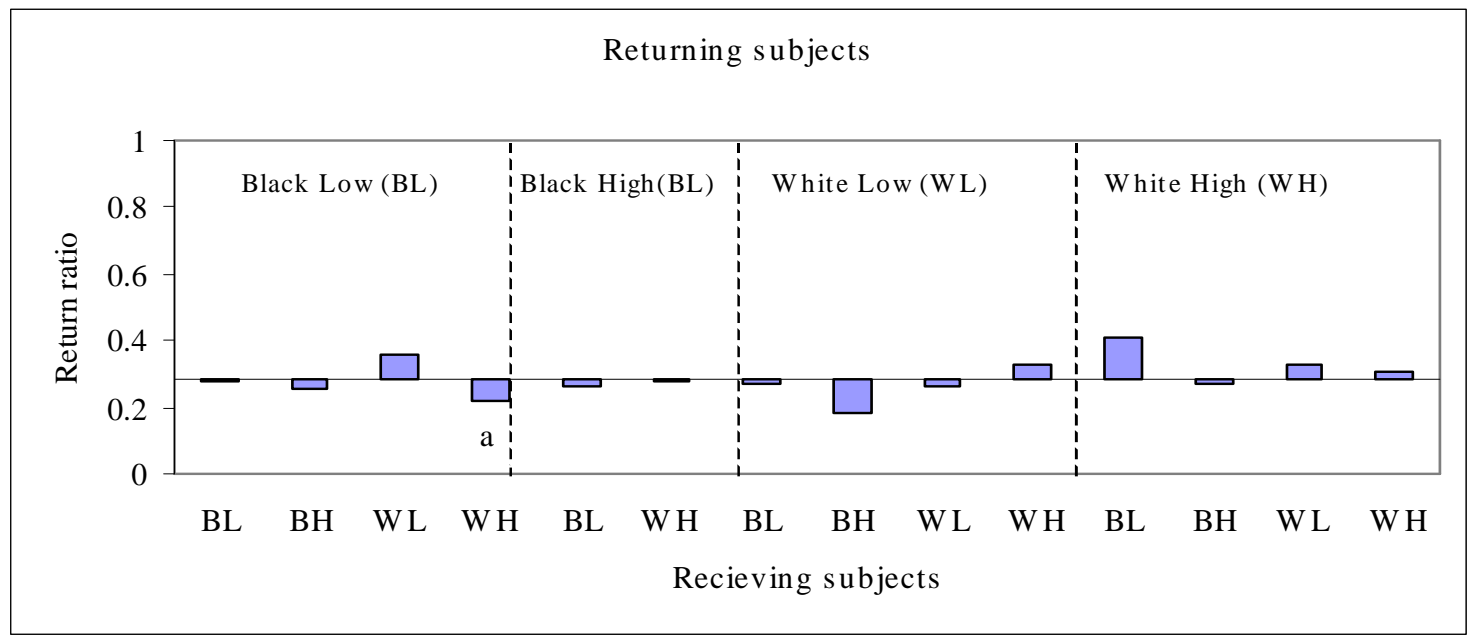

Figure 4. Average return ratio

Note: The bars represent the average return ratio in each socio-economic group (sub-title on top) in partnerships with subjects of each socio-economic group (indicated on the X-axis). (a) Significantly lower return ratio in partnerships with WH than with WL.

Figure 5 displays the average investment ratios that were expected in each type of partnership by the receiving subjects in each of the socio-economic groups. As in the previous figures, the average investment ratio expected in the "no information" treatment is used as a benchmark. In general, the expressed expectations are not significantly distinguishable from the benchmark. Nevertheless, two interesting observation can be made. First, in many cases where an above benchmark investment ratio was expected, the actual investment ratio was below zero and vice versa. In other words, the expectations are not always well aligned with the actual behaviour. Second, the only significant effects observed relate to the expectations of white subjects concerning the investment ratios of BH and WL subjects. All white subjects 
expect too low investment ratios by $\mathrm{BH}$ subjects and too high investment ratios by the WL subjects, when compared to the actual investment behaviour.

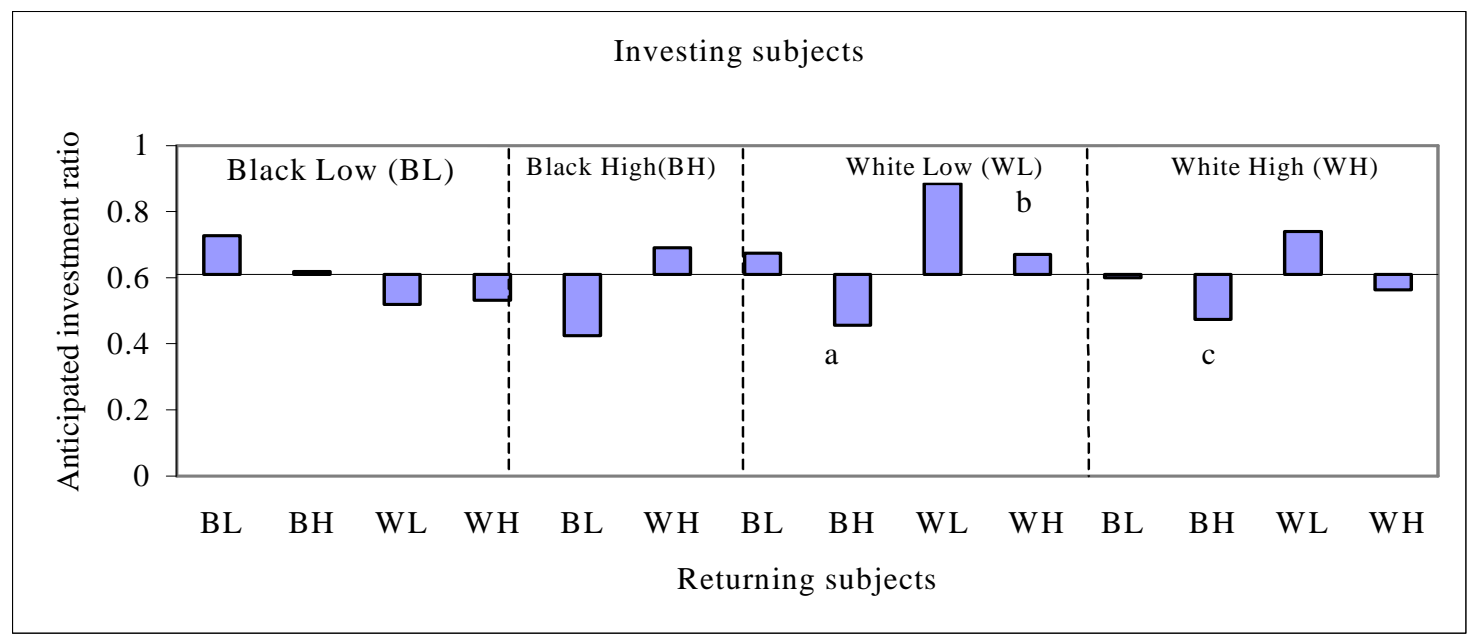

Figure 5. Average anticipated investment ratio.

Note: The bars represent the average investment ratio expected in each socio-economic group (sub-title on top) in partnerships with subjects of each socio-economic group (indicated on the X-axis). (a) Significantly lower investment ratio expected in partnerships with BH than with WL. (b) Significantly lower investment ratio expected in partnerships with WH than with WL. (c) Significantly lower investment ratio expected in partnerships with BH than with WL.

\subsection{Payoff consequences}

In the analysis so far, we focused on detecting differential behaviour and expectations. When subjects' choices were in conflict with their expectations of monetary income, we could localize a preference for differential treatment for which a payoff disadvantage was taken into account. In this section we pursue the question how the observed behaviour translates into payoffs for the different subject types. Since we have elicited strategies from our subjects, we can create a more complete picture of the distribution of payoffs by calculating the average payoff each subject would have had, if we had matched him/her to every possible counterpart from the corresponding socio-economic group. The top two panels in Figure 5 show the averages of these population payoffs for the investors and the receivers, correspondingly. The lowest panel displays the average income of both roles in each of the socio-economic groups. The "no information" benchmark is once again provided to allow a visual assessment of the effect of socio-economic information on the payoffs achieved in the game. 

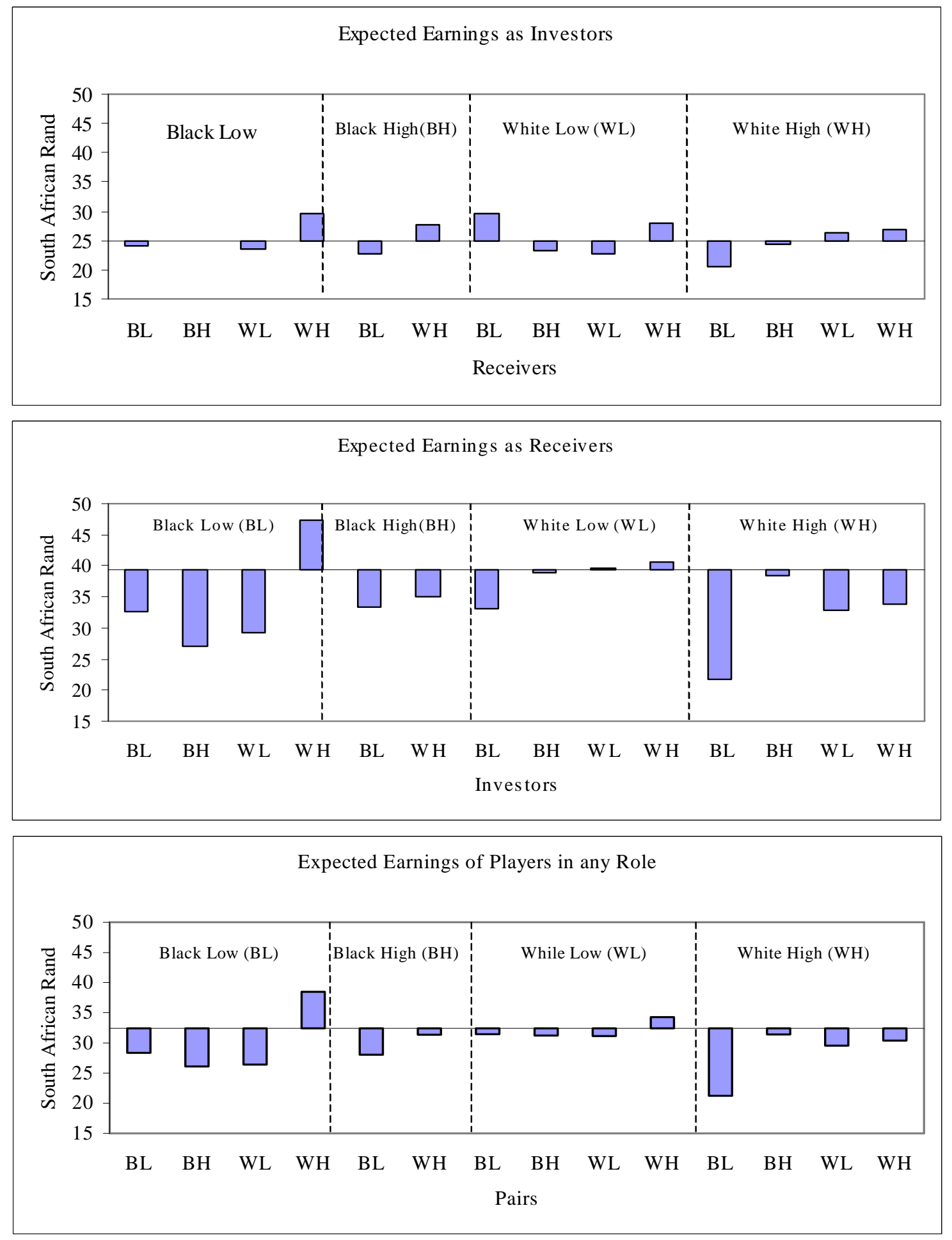

Figure 6. Average payoffs.

Note: The bars represent the average payoff of the corresponding players in each socio-economic group (sub-title on top) in partnerships with subjects of each socio-economic group (indicated on the X-axis). For the WL subjects linked to $\mathrm{BH}$ subjects we have no observations on the latter. In this case, we therefore determined the WL payoffs by drawing from observations from a pilot. 
The general picture that emerges from Figure 6 is that socio-economic information has an adverse effect on the behaviour in partnerships leading to negative payoff consequences. This holds in particular for BL subjects who are on the losing side in all but one of the possible partnerships. Only BL subjects in partnerships with WH subjects earn substantially more than in the "no information" benchmark. This is mainly due to the fact that WH subjects invest significantly more in partnerships with a BL receiver than in the "no information" benchmark, but receive significantly less from the BL subjects. While WH subjects are acting more generously than they would without information, the BL subjects are behaving less generously than they would without information. It is not surprising that the strongest payoff effects of the socio-economic information are present in this specific relationship, in which subjects exhibit preferences for differential treatment that are not based on monetary incentives.

\section{Determinants of Experimental Decisions}

In this section, we report a series of regression analyses that help to quantify the observed effects of the socio-economic information given to the subjects. Additionally, the regressions are used to check for correlations of the observed behaviour to the questionnaire answers provided by the subjects. We can confirm that low-income subjects send significantly less than other subjects if they are linked to high-income subjects of the other race. Moreover, we show that the questionnaire responses do not provide reliable forecasts on subjects' behaviour. First, the regressions explaining the investment ratio are reported and then the regressions explaining the return ratio.

\subsection{Investment Ratio}

We used a double-censored Tobit regression with the investment ratio as the dependent variable. The results are summarized in Table 4 . The variable names are self-explanatory. (See Appendix B for the definitions of variables that are reported.)

Column 1 contains the coefficient estimates for the regression in which only the basic characteristics of the sender and the receiver are included. None of the coefficients are significant. In particular, not even the dummy variable "social distance," which is equal to one when both the race and the income levels of the matched individuals are different, has significant explanatory power for the observed variations in the chosen investment ratios. This 
may seem surprising on first sight, but is intuitively clear when we take into consideration that the observed behaviour towards subjects from another race and income group is asymmetric, since the low income subjects hold back investments in partnerships with high income subjects from the other race, but the opposite is not true. In column 2, we introduce a dummy variable called "income*soc," which is equal to one when the sender has a low income and is matched with a subject of both a different race and a different income level. As expected, the coefficient of this variable is highly significant, conforming our experimental results.

In column 3, questionnaire items measuring subjects' perceptions of equity and fairness are included. None of the coefficients are significant. Finally, in column 4, subjects' expectation of the amount invested and returned by their partner is included in the regression. The coefficient on the expected return ratio is positive and significant, suggesting that in general subjects' own investment behaviour is driven by what they expect their counterparts to return.

Table 4. Double-Censored Tobit Estimates on the INVESTMENT RATIO

\begin{tabular}{|c|c|c|c|c|}
\hline & 1 & 2 & 3 & 4 \\
\hline CONSTANT & $0.525(0.111)$ & $0.493(0.109)$ & $0.604(0.181)$ & $0.198(0.176)$ \\
\hline MALE & $-0.059(0.071)$ & $-0.069(0.069)$ & $-0.063(0.074)$ & $-0.049(0.063)$ \\
\hline LOW INCOME & $-0.144(0.082)$ & $-0.062(0.086)$ & $-0.050(0.091)$ & $-0.124(0.078)$ \\
\hline WHITE & $0.127(0.078)$ & $0.096(0.077)$ & $0.082(0.084)$ & $0.046(0.070)$ \\
\hline INCOME-HETRO & $0.056(0.098)$ & $0.057(0.096)$ & $0.081(0.097)$ & $0.141(0.084)$ \\
\hline RACE-HETRO & $0.034(0.104)$ & $0.034(0.101)$ & $0.035(0.102)$ & $0.137(0.088)$ \\
\hline SOCIAL DISTANCE & $-0.161(0.143)$ & $0.179(0.194)$ & $0.171(0.195)$ & $0.055(0.169)$ \\
\hline INCOME*SOC & & $-0.462(0.184)$ & $-0.487(0.189)$ & $-0.372(0.161)$ \\
\hline PERCEPTIONS & & & $-0.047(0.041)$ & $-0.050(0.036)$ \\
\hline OPPORTUNITY & & & $0.023(0.074)$ & $-0.010(0.062)$ \\
\hline EDUCATION & & & $0.054(0.084)$ & $0.046(0.071)$ \\
\hline TRUST INDEX & & & $-0.034(0.051)$ & $-0.034(0.044)$ \\
\hline EXP. INVEST RATIO & & & & $-0.054(0.161)$ \\
\hline EXP. RETURN RATIO & & & & $0.716(0.106)$ \\
\hline$\Sigma$ & $0.409(0.031)$ & $0.398(0.030)$ & $0.397(0.030)$ & $0.331(0.025)$ \\
\hline Log likelihood & -98.988 & -95.863 & -94.656 & -69.322 \\
\hline Wald Test $\left(\chi^{2}\right)$ & 13.1 & 19.35 & 21.6 & 68.1 \\
\hline Observations & 144 & 144 & 143 & 141 \\
\hline
\end{tabular}

Numbers in parentheses are the estimated standard errors. 


\subsection{Return Ratio}

The estimated coefficients of the return ratio regressions are summarized in Table 5. Since we used the strategy method, we have more than one observation for each respondent. In particular, each respondent had to state how much to return for each of the eleven possible amounts that could be received from the sender. To take the panel character of this data set into account, we employed the random effects tobit model.

Table 5. Single Censored Tobit Estimates of the RETURN RATIO

\begin{tabular}{|c|c|c|c|c|}
\hline & 1 & 2 & 3 & 4 \\
\hline CONSTANT & $-0.181(0.032)$ & $-0.189 \quad(0.032)$ & $-0.034 \quad(0.039)$ & $-0.198 \quad(0.041)$ \\
\hline$\Theta$ & $0.014(0.001)$ & $0.014 \quad(0.001)$ & $0.015 \quad(0.001)$ & $0.015 \quad(0.001)$ \\
\hline$\Theta^{2}$ & $-0.0001(0.00001)$ & $-0.0001 \quad(0.00001$ & $-0.0001 \quad(0.00001)$ & $-0.0001 \quad(0.00001)$ \\
\hline MALE & $0.073(0.015)$ & $0.039(0.012)$ & $0.011(0.013)$ & $0.004 \quad(0.012)$ \\
\hline LOW INCOME & $-0.051 \quad(0.017)$ & $-0.034 \quad(0.014)$ & $-0.003(0.014)$ & $-0.066 \quad(0.014)$ \\
\hline WHITE & $-0.004(0.015)$ & $0.027 \quad(0.014)$ & $-0.038(0.012)$ & $(0.013)$ \\
\hline INCOME-HETRO & $0.005(0.017)$ & $0.003(0.015)$ & $-0.025(0.013)$ & $-0.035 \quad(0.014)$ \\
\hline RACE-HETRO & $-0.017(0.019)$ & $(0.017)$ & $0.043 \quad(0.0211)$ & $(0.016)$ \\
\hline SOCIAL DISTANCE & $-0.011(0.029)$ & $0.047 \quad(0.026)$ & $0.144 \quad(0.031)$ & $(0.026)$ \\
\hline INCOME*SOC & & $-0.12(0.039)$ & $-0.201(0.024)$ & $(0.025)$ \\
\hline PERCEPTIONS & & & $-0.03 \quad(0.006)$ & $0.01 \quad(0.005)$ \\
\hline OPPORTUNITY & & & $-0.048 \quad(0.01)$ & $-0.021 \quad(0.013)$ \\
\hline EDUCATION & & & $0.004 \quad(0.015)$ & $-0.008 \quad(0.012)$ \\
\hline TRUST INDEX & & & $-0.023 \quad(0.007)$ & $0.02 \quad(0.008)$ \\
\hline EXP. INVEST RATIO & & & & $0.212 \quad(0.023)$ \\
\hline EXP. RETURNRATIO & & & & $0.019 \quad(0.008)$ \\
\hline$\Sigma e$ & $0.17 \quad(0.005)$ & $0.169 \quad(0.005)$ & $0.182 \quad(0.005)$ & $0.174 \quad(0.004)$ \\
\hline$\Sigma \mathrm{u}$ & $0.137 \quad(0.003)$ & $0.136 \quad(0.003)$ & $0.0134 \quad(0.003)$ & $0.0135 \quad(0.003)$ \\
\hline Rho & $0.607 \quad(0.016$ & $0.607 \quad(0.017)$ & $0.646 \quad(0.014)$ & $0.624 \quad(0.015)$ \\
\hline Log likelihood & 447.833 & 456.152 & 465.68 & 462.46 \\
\hline Wald Test $\left(\chi^{2}\right)$ & 511.51 & 595.96 & 718.63 & 760.77 \\
\hline Observations & 1573 & 1573 & 1562 & 1550 \\
\hline
\end{tabular}

Numbers in parentheses are the estimated standard errors. 
The return ratio is positively correlated to the amount available to the subject, $\Theta$. However, since the return ratio increases as a decreasing rate, there is a negative effect of the square of the amount available. The baseline regression also includes the characteristics of both the investor and responder, as reported in column 1 of Table 5. It seems that males return more, while low income participants return less. Neither income nor race heterogeneity, however, seems to play a role in responder's decision on the return. And again, as in the case of the investments, the symmetric cross-effect of income and race ("social distance") is not significant, while the asymmetric cross-effect ("income*soc") has a significantly negative effect on the return ratio, thus conforming the negative effect of cross-cultural envy.

Adding the questionnaire responses to the regression (column 3), provides significantly negative, but very small effects for the "perceptions" and "trust index" variables, which indicate whether the subject perceives inequality as having been generated fairly and whether the subject generally trusts others, correspondingly. However, since both coefficients switch to positive, as soon as we add the expectation on investment and return (in column 4), it seems that the actual effect of these variables cannot be measured very precisely. But, there is a significantly positive effect between the expected investment and return measures and the return ratio.

\section{Concluding remarks}

We report the results of a series of experimental trust games conducted in South Africa focusing on the effects of racial and income inequality on cooperation in partnerships. We vary the amount of socio-economic information available to the subjects about their counterparts in order to assess the effect of inequality between the partners. In the control treatment, in which no such information is provided, we observe no significant differences in the behaviour across races and income groups. In fact, despite the extreme heterogeneity of the South African society, we find that the general level of trust and trustworthiness observed in the control treatment is very similar to what is observed in more homogenous societies.

When socio-economic information on their counterparts is provided to the subjects, individual trust behaviour is affected significantly. While we neither observe simple racial nor simple income-based discrimination, we do observe that the low income subjects from both racial groups invest significantly less in partnerships with the high income subjects of the other racial group than in any other partnership. Interestingly, the exceptionally low investment

ratios, that are observed in these "maximal distance" partnerships, cannot be attributed to 
particularly low return expectations. Hence, it seems clear that the motivation for such behaviour is genuinely non-monetary and perhaps best described as "cross-racial envy."

Interestingly, with the one exception of black high-income subjects in partnerships with lowincome subjects of their own race, we find no differentiating or discriminatory action by highincome subjects towards other groups. This outcome is especially surprising, not only because of the history of "white supremacy" in South Africa, but also because the relative cost of discrimination is lower for the high-income groups than for the low-income groups (i.e. the efficiency loss in a mixed partnership hurts the rich less than it hurts the poor). It remains an open issue, whether the political changes of the last decades have created a social consensus of non-discrimination amongst the high-income white South Africans ${ }^{16}$ or whether the norm of non-discrimination had evolved earlier and was then at the root of the political process. In either case, our finding indicates a fundamental support of the anti-apartheid norms by the high-income white subjects, even when they have to "put their money where their mouth is," i.e. bear the financial risk and cost of their non-discriminatory actions.

Although the results of this study, like those of most other micro-economic studies, must only be cautiously generalised to the macro-economic level, we do believe to have found some evidence with macro-economic implications. On the one hand, it seems that substantial socioeconomic gaps in an economy, i.e. great cultural diversity and considerable inequality, may interact to create inefficiencies due to distrust and discrimination. Hence, we find some support for the growing body of literature that indicates that closing the "gaps" may actually increase economic efficiency. On the other hand, however, our results also seem to indicate that the genesis of inequality affects the attitudes and the behaviour of the economic agents. Thus, we must conclu3de that socio-economic differences may affect behaviour in different ways, depending on the history of social interaction. The history of social interaction in South Africa, for example, may explain why high-income black subjects may have less scruples to discriminate against others than high-income white subjects.

Finally, since the provision of socio-economic information may exacerbate the inefficiency caused by distrust and discrimination, states with high degrees of social diversity and economic inequality may be well-advised to create institutions that mask all personal

\footnotetext{
${ }^{16}$ In particular, for this group the introduction of democratic institutions after the breakdown of apartheid may have generated the confidence that mutually beneficial policy outcomes would be adopted by the black majority, in line with Collier's (2001) findings that democracy can mitigate detrimental effects of ethnic diversity.
} 
attributes of investors. This may be achieved by installing (trusted) government financing or (controlled) impersonal investment and venture capital corporations.

\section{References}

Alesina, A., Baqir, R., Easterly, W. (1999): "Public Goods and Ethnic Divisions," Quarterly Journal of Economics 114 (4), 1243-1284.

Alesina, A., La Ferrara, E. (2002): “Who Trusts Others?” Journal of Public Economics 85, 207-234.

Berg, J., Dickhaut, J. \& McCabe, K. (1995): “Trust, Reciprocity and Social History," Games and Economic Behavior 10, 122-142.

Berg, Servaas van der and Burger ,Ronelle (2000): "The stories behind the numbers: an investigation of efforts to deliver services to the South African poor," World Bank Working Paper no 26935.

Barr, Abigail (2003): “Trust and Expected Trustworthiness: Experimental Evidence From Zimbabwean Villages," Economic Journal 113, 614-630.

Burns, Justine (2004): "Insider-Outsider Distinctions in South Africa: The impact of race on the behavior of High School Students, " mimeo, University of Cape Town.

Camerer, Colin (2003): Behavioural Game Theory: Experiments on Strategic Interaction, Princeton University Press, Princeton, NJ.

Carter, Michael R, and Castillo, Marco (2002): "The Economic Impact of Altruism, Trust and Reciprocity: An Experimental Approach to Social Capital," Wisconsin-Madison Agricultural and Applied Economics Staff Papers 448.

Collier, Paul (2001): "Implications of ethnic diversity”, Economic policy 16, 127-166.

Eckel, Catherine C., and Wilson, Rick K. (2003): "Conditional trust: sex, race and facial expressions in a trust game," mimeo, Virgina Tech and Rice University.

Easterly, W., and Levine, R. (1997): “Africa's Growth Tragedy: Policies and Ethnic Divisions,” Quarterly Journal of Economics 112, 1203-1250.

Fershtman, Chaim and Gneezy, Uri (2001): "Discrimination in a Segmented Society: An Experimental Approach," Quarterly Journal of Economics 116, 351-377.

Glaeser, E., Laibson, D.I., Scheinkman, J.A., and Soutter C.L. (2000): “Measuring Trust,” Quarterly Journal of Economics 115, 811-846.

Haddad, L. and Maluccio, J. (2003): "Trust, Membership in Groups, and Household Welfare: Evidence from KwaZulu-Natal, South Africa," Economic Development and Cultural Change 51, 573-600.

Henrich, Joseph, Robert Boyd, Sam Bowles, Colin Camerer, Herbert Gintis, Richard McElreath and Ernst Fehr (2001): "In search of Homo economicus: Experiments in 15 Small-Scale Societies," American Economic Review 91, 73-79.

Knack, Stephen and Keefer, Philip (1997): "Does Social Capital Have an Economic Payoff? A Cross-Country Investigation," Quarterly Journal of Economics 112, 1251-1288.

La Ferrara, E. (2002): “Inequality and group participation: theory and evidence from rural Tanzania,” Journal of Public Economics 85, 235-273.

La Porta, R., Lopez-de-Silanes, F., Shleifer, A, and Vishny, R. (1997): “Trust in Large Organizations,” American Economic Review Papers and Proceedings 87, 333-338.

Maluccio, J., Haddad, L., and May, J. (2000): "Social Capital and Household Welfare in South Africa, 1993-98," Journal of Development Studies 36, 54-81.

Stewart, Frances (2002): "Horizontal Inequalities: A Neglected Dimension of Development," WIDER Working Paper 8. 


\section{Appendix A: Instructions}

Welcome to our experiment, which is part of a research project of Tilburg University in co-operation with the North West University. In this experiment you can earn real money that will be paid to you privately in cash at the end of the experiment. Because participants take part in the experiment at different times and places, the experiment may not end today. After the session, we will inform you when and where you can pick up your payoff. How much money you will receive in the end depends on your decisions and the decisions of other participants of the experiment.

We will read these instructions together. After this you will have ample opportunity to ask questions. If you have a question by then, please raise your hand and we will help you.

\section{Description}

In this experiment, you will be randomly matched to another participant. Both of you start with an endowment of 20 Rand. Each of you will decide what amount of money to transfer to the other. You will decide one after the other. The first to decide is called player A, the second to decide is called player B. For now you do not know whether you are player A or B. You will be informed later.

If you are player A, you will decide how much of your initial endowment (20 Rand) you want to transfer to player B. The amount that you transfer to player B must be an even number that means a number from the set $\{0$, $2,4,6,8,10,12,14,16,18,20\}$. Your transfer to B will be tripled by the experimenter. For example, if you are player A and transfer 4 Rand to player B, the amount that B will actually receive is 3 x $4=12$ Rand. Note that you can decide not to transfer money to player B. If you do not, then nothing is tripled and each of you will have the original 20 Rand to take home.

If you are player B, you will receive the tripled amount of money that was transferred to you by player A. This tripled amount is added to your initial endowment of 20 Rand. For example, if you are player B and player A has transferred 4 Rand to you, then you will have total amount of $20+12=32$ Rand. Now, you can decide to transfer some part of your total earnings to A. Your transfer to A is not tripled. The remaining part of your total earnings (the amount that you did not transfer to A) is your payoff of the experiment. Note that you can decide not to transfer money to player A. If you do not, then you will have your total earnings to take home, while A will have the original endowment minus the transfer made to you.

\section{Decision Form (with information on partner)}

This is the decision form that you must fill out. You will make decisions both for the role as player A and as player B. A random draw will later determine whether you are actually player A or player B.

Upon registration, the participant to whom you are matched has provided the following information*):

Race [] [] black [] other

Family Income [ ] below average [ ] above average

The corresponding information that you have provided is also given to the participant you are matched with.

\section{Suppose you are player A}

Please, fill in your decisions as player A on the blanks in the lines 1) and 2).

1) Your transfer to player $B$ is Rand

Remember that you may only choose an even number.

So, you may choose from: 0, 2, 4, 6, 8, 10, 12, 14, 16, 18, or 20.

2) You expect $B$ to transfer to you

Rand

\section{Suppose you are player B}

The table below lists all possible amounts that player A may send to you. If you are randomly determined to be player B, only one of these amounts will actually count, namely the one that was chosen by the player A who is

\footnotetext{
${ }^{*}$ In the no information treatment, no information on race and income is provided to the subjects.
} 
matched to you. But, since for now you do not know which amount will actually be chosen by player A, you must make a transfer decision for every possible amount..

\begin{tabular}{|c|c|c|c|c|c|c|c|c|c|c|c|}
\hline A transfers & 0 & 2 & 4 & 6 & 8 & 10 & 12 & 14 & 16 & 18 & 20 \\
\hline A retains & 20 & 18 & 16 & 14 & 12 & 10 & 8 & 6 & 4 & 2 & 0 \\
\hline $\mathrm{B}$ receives & 0 & 6 & 12 & 18 & 24 & 30 & 36 & 42 & 48 & 54 & 60 \\
\hline B has & 20 & 26 & 32 & 38 & 44 & 50 & 56 & 62 & 68 & 74 & 80 \\
\hline B transfers & & & & & & & & & & & \\
\hline
\end{tabular}

Please, fill in a transfer to A in each of these empty cells.

Make sure that the transfer you fill in is not greater than the amount in the cell immediately above it.

You expect A to transfer to you

Rand

Remember that A may only choose an even number.

So, A may choose from: 0, 2, 4, 6, 8, 10, 12, 14, 16, 18, or 20. 
Appendix B. Summary statistics of variables used in regressions

\begin{tabular}{|c|c|c|}
\hline VARIABLES & Mean StD. & Definition of Variables used \\
\hline MALE & 0.4730 .45 & Dummy 1 if male \\
\hline LOW INCOME & 0.6460 .479 & Dummy 1 if family income is below average \\
\hline WHITE & 0.4590 .498 & Dummy 1 if white \\
\hline EDUCATION & 0.4650 .500 & Dummy 1 if parents have college degree \\
\hline PERCEPTION & 2.8500 .869 & $\begin{array}{l}\text { Index of economic position based on ability, based on questionnaire responses from } 1 \\
\text { (disagree strongly) to } 4 \text { (agree strongly) }\end{array}$ \\
\hline OPPORTUNITY & $0.479|0.500|$ & Dummy 1 if subjects perceive equality in opportunity \\
\hline TRUST INDEX & 0.7060 .707 & Index of GSS fair, trust and help \\
\hline INCOME-HETRO & $0.534|0.500|$ & Dummy 1 if match is different in income \\
\hline RACE-HETRO & 0.4790 .500 & Dummy 1 if match is different in race \\
\hline SOCIAL DISTANCE & 0.2500 .433 & Interactive term for INCOME-HETRO*RACE-HETRO \\
\hline INCOME*SOC & 0.1870 .390 & Interactive term for INCOME and SOCIAL DISTANCE \\
\hline AMOUNT SENT & 0.4510 .321 & Amount sent out of available stake \\
\hline RETURN RATIO & $0.285|0.224|$ & Amount returned out of available amount \\
\hline EXP. RETURN RATIO & 0.3670 .207 & Expected return out of available amount \\
\hline EXP. INVEST RATIO & 0.6060 .311 & Expected amount sent out of available amount \\
\hline
\end{tabular}

